\title{
Induction of Serum Amyloid A3 in Mouse Mammary Epithelial Cells Stimulated with Lipopolysaccharide and Lipoteichoic Acid
}

\author{
Sato Kamiya ${ }^{1}$, Kaori Shimizu ${ }^{1}$, Ayaka Okada ${ }^{1,2}$ and Yasuo Inoshima ${ }^{1,2,3,4, *}$ \\ 1 Laboratory of Food and Environmental Hygiene, Cooperative Department of Veterinary Medicine, \\ Faculty of Applied Biological Sciences, Gifu University, Gifu 501-1193, Japan; \\ Nana.sa08to03.cl@gmail.com (S.K.); skaori@gifu-u.ac.jp (K.S.); okadaa@gifu-u.ac.jp (A.O.) \\ 2 Education and Research Center for Food Animal Health, Gifu University (GeFAH), Gifu 501-1193, Japan \\ 3 Joint Graduate School of Veterinary Sciences, Gifu University, Gifu 501-1193, Japan \\ 4 The United Graduate School of Veterinary Sciences, Gifu University, Gifu 501-1193, Japan \\ * Correspondence: inoshima@gifu-u.ac.jp; Tel.: +81-58-293-2863
}

\section{check for} updates

Citation: Kamiya, S.; Shimizu, K.; Okada, A.; Inoshima, Y. Induction of Serum Amyloid A3 in Mouse Mammary Epithelial Cells Stimulated with Lipopolysaccharide and Lipoteichoic Acid. Animals 2021, 11, 1548. https://doi.org/ 10.3390/ani11061548

Academic Editors: Piotr Baska, Olga Witkowska-Piłaszewicz and Katarzyna Basałaj

Received: 7 April 2021

Accepted: 23 May 2021

Published: 25 May 2021

Publisher's Note: MDPI stays neutral with regard to jurisdictional claims in published maps and institutional affiliations.

Copyright: (c) 2021 by the authors. Licensee MDPI, Basel, Switzerland. This article is an open access article distributed under the terms and conditions of the Creative Commons Attribution (CC BY) license (https:/ / creativecommons.org/licenses/by/ $4.0 /)$.
Simple Summary: Serum amyloid A (SAA) is an acute phase protein present in mammals and birds. Based on the amino acid sequence, SAA has been classified into isoforms SAA1-4 in mice. Previously, it was reported that after the stimulation with bacterial antigens, the expression of the Saa3 mRNA was induced more strongly than that of the Saa1 mRNA in mouse epithelia, including colonic and alveolar epithelial cells, indicating that SAA3 plays a role in the local response. However, the contribution of SAA3 to the local response in mouse mammary epithelium, where mastitis occurs due to bacterial infection, has not been completely determined yet. In this study, to clarify whether mouse SAA3 has a role in the defense against bacterial infection in mouse mammary epithelium, normal murine mammary gland (NMuMG) epithelial cells were stimulated with lipopolysaccharide (LPS) and lipoteichoic acid (LTA). LPS and LTA significantly enhanced mRNA expression level of the Saa3 gene but not that of Saa1. Furthermore, LPS induced SAA3 protein expression more strongly than LTA. Our data indicate that SAA3 expression in mouse mammary epithelial cells was increased by the stimulation with bacterial antigens, suggesting that SAA3 is involved in the defense against bacterial infection in mouse mammary epithelium.

Abstract: In this study, to establish whether serum amyloid A (SAA) 3 plays a role in the defense against bacterial infection in mouse mammary epithelium, normal murine mammary gland (NMuMG) epithelial cells were stimulated with lipopolysaccharide (LPS) and lipoteichoic acid (LTA). LPS and LTA significantly enhanced mRNA expression level of the Saa3 gene, whereas no significant change was observed in the Saa1 mRNA level. Furthermore, LPS induced SAA3 protein expression more strongly than LTA, whereas neither LPS nor LTA significantly affected SAA1 protein expression. These data indicate that the expression of SAA3 in mouse mammary epithelial cells was increased by the stimulation with bacterial antigens. SAA3 has been reported to stimulate neutrophils in the intestinal epithelium and increase interleukin-22 expression, which induces activation of the innate immune system and production of antibacterial proteins, such as antimicrobial peptides. Therefore, collectively, these data suggest that SAA3 is involved in the defense against bacterial infection in mouse mammary epithelium.

Keywords: lipopolysaccharide; lipoteichoic acid; mouse mammary epithelial cells; serum amyloid A1; serum amyloid A3

\section{Introduction}

Systemic amyloid A (AA) amyloidosis is a severe complication of inflammation associated with life-threatening diseases such as rheumatoid arthritis, Crohn's disease, and 
gout in humans, but it is also observed in other mammalian species and in birds [1,2]. This disease is caused by the conformational conversion of the circulating soluble precursor protein, serum amyloid A (SAA), into insoluble amyloid fibrils [3]. These fibrils accumulate extracellularly and form deposits in various organs, resulting in fatal organ dysfunction [2]. Chronically high concentrations of blood SAA facilitate the conversion into AA amyloid fibrils [2]. SAA is secreted as an acute phase reactant by the liver under the transcriptional control of interleukin-1 (IL-1) and IL-6 [2]. Blood SAA level increases up to 1000 -fold following inflammatory stimulation, and this property makes SAA a biomarker of inflammation, injury, and cancers in humans and animals [4,5]. Based on the amino acid sequence, four SAA isoforms, SAA1-4, have been distinguished in mice. SAA1 and SAA2 genes and proteins (GenBank accession nos. BC087933 and M11130) share $95.1 \%$ and $92.6 \%$ sequence identities in 396 nucleotides and 122 amino acids, respectively. On the other hand, nucleotide and amino acid sequence identities between SAA1 and SAA3 (NM011315) are $74.3 \%$ and $64.7 \%$, respectively (Figure 1). From these sequence differences, it can be concluded that SAA1 and SAA3 have different physiological functions. SAA1 and SAA2 are predominantly produced in the liver as acute phase proteins; they cause formation of AA amyloid fibrils and can be used as biomarkers of inflammation [2,6]. In contrast, SAA3 is mainly expressed in extrahepatic tissues, such as the intestines, the adipose tissue, and the lung, and it does not contribute to the overall SAA level in blood [6-9]. Previous studies using SAA3 knockout mice demonstrated that SAA3 regulated normal lung development and was required for metabolic function including normal weight $[10,11]$, and SAA3 protects epithelium against acute injuries in colitis [12] and in the lung infected with Pseudomonas aeruginosa [13] through induction of neutrophils. In mouse lung, SAA3 stimulates toll-like receptor (TLR) 4 and causes inflammation-like state in early pulmonary metastasis [14]. Mouse SAA3 positively correlates with increased cellular maturation of osteocytes and controls bone development and homeostasis [15]. In vitro studies also reported that Saa 3 mRNA expression was strongly induced by bacterial antigens in mouse colonic epithelial CMT-93 cells [9,16], type-II alveolar epithelial MLE-15 and T7 cells [17], and pulmonary epithelial Club (Clara) C22 cells [18]. In contrast, Saa1 mRNA expression was not induced by bacterial antigens in any of the mouse epithelial cells, even though Saa1 mRNA expression was detectable in those cells [9,16-18]. Furthermore, the recombinant SAA3 protein up-regulated Mucin 2 mRNA expression in CMT-93 cells [16,19]. Mucin is a component of the mucus layer, which acts as an epithelial barrier to pathogens [20]. It has been also reported that the presence of SAA3 reduces the severity of non-bacterial infectious colitis [12]. These findings suggest that SAA3 plays a role in the prevention of bacterial infections and in the inflammation during local immunity reactions in mouse epithelium.

However, the relationship between SAA3 expression and local immunity in mouse mammary epithelial cells has not yet been completely elucidated. The purpose of this study was to clarify if SAA3 expression could be up-regulated by the stimuli resembling bacterial infection in mouse mammary epithelial cells. Here, quantitative real-time polymerase chain reaction (PCR), indirect immunofluorescence assay (IFA), and Western blotting (WB) were performed to investigate changes in the expression levels of SAA3 mRNA and protein in mouse mammary epithelial cells after stimulation with bacterial antigens. 


SAA1 (BC087933)
SAA2 (BC024606)
SAA2 (M11130)
SAA3 (NM011315)
SAA4 (BC019212)
SAA1 (BC087933)
SAA2 (BC024606)
SAA2 (M11130)
SAA3 (NM011315)
SAA4 (BC019212)

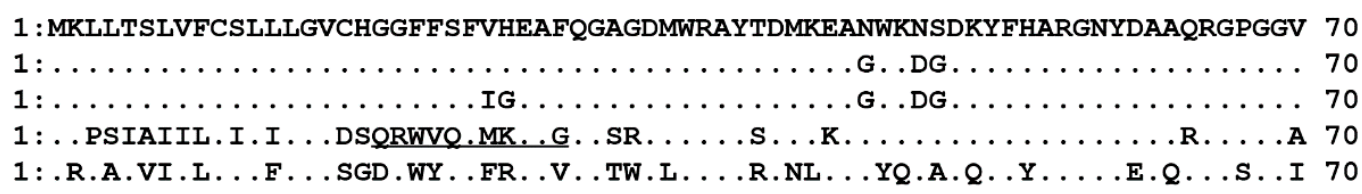

Figure 1. Alignment of amino acid sequences of mouse serum amyloid A (SAA) isoforms. The sequences (AAEKISDGREAFOE and QRWVQFMKEAG) of synthetic SAA1 and SAA3 peptides for immunization to rabbits are underlined. Accession numbers are shown in parentheses.

\section{Materials and Methods}

\subsection{Cells}

Normal murine mammary gland (NMuMG) epithelial cells were purchased from the European Collection of Authenticated Cell Cultures General Cell Collection, Public Health England (94081121, Salisbury, UK). The cells were maintained in Dulbecco's modified Eagle's minimum essential medium (DMEM, \#044-29765, Wako, Osaka, Japan) supplemented with 10\% fetal bovine serum (FBS) (\#A15-701, lot. A70109-0524, PAA Laboratories, Pasching, Austria) and $10 \mu \mathrm{g} / \mathrm{mL}$ insulin (\#I0516, Sigma-Aldrich, St. Louis, MO, USA) in a collagen-coated dish (\#NCO430167, Corning, Corning, NY, USA).

\subsection{Treatment with Lipopolysaccharide (LPS) and Lipoteichoic Acid (LTA) for mRNA Expression Analysis}

NMuMG cells were seeded at a density of $4 \times 10^{5}$ cells/well in 6-well collagencoated plates (\#NCO3506, Corning, Corning, NY, USA) and incubated for $15 \pm 1 \mathrm{~h}$ before experiments. After incubation, the cells were rinsed with sterile phosphate-buffered saline (PBS) and treated with LPS from Escherichia coli O111:B4 (\#115K4029, Sigma-Aldrich, St. Louis, MO, USA) or lipoteichoic acid (LTA) from Bacillus subtilis (L3265, Sigma-Aldrich), which are outer membrane proteins of the Gram-negative and Gram-positive bacteria, respectively. Because our previous studies indicated significantly different responses in cultured mouse colonic, type-II alveolar, and pulmonary epithelial cells [16-18], LPS and LTA were diluted to $10 \mu \mathrm{g} / \mathrm{mL}$ in DMEM without FBS. NMuMG cells treated with LPS or LTA were incubated for $2 \mathrm{~h}$ at $37^{\circ} \mathrm{C}$ in a $5 \% \mathrm{CO}_{2}$ atmosphere.

\subsection{RNA Extraction, cDNA Synthesis, and Quantitative Real-Time PCR}

For RNA extraction, LPS or LTA-treated cells were collected from the plates by cell lifters. RNA was extracted from the cells immediately using an RNeasy Mini Kit (\#74106, Qiagen, Hilden, Germany) following the manufacturer's instructions. Extracted RNA was quantified using a NanoDropLite spectrophotometer (Thermo Fisher Scientific, Wilmington, DE, USA) and stored at $-80^{\circ} \mathrm{C}$ until use. Contaminating DNA was eliminated by DNase I (\#18068-015, Invitrogen, Carlsbad, CA, USA) treatment, and cDNA was synthesized as described previously [17]. Synthesized cDNA was used for quantitative real-time PCR analysis by using a StepOnePlus thermal cycler (Applied Biosystems, Foster City, CA, USA) as described previously [17].

To evaluate mRNA expression of the Saa1, Saa3, and glyceraldehyde-3-phosphate dehydrogenase (Gapdh) genes, their specific primers were used for quantitative real-time PCR (Table 1). mRNA expression was normalized to that of the reference gene Gapdh, which was reported to be a suitable reference gene in NMuMG cells [21], and fold-changes relative to control levels were determined by the $\Delta \Delta C T$ method [22]. For the verification of specific 
amplification, a melting-curve analysis of amplification products was performed at the end of each PCR reaction. All experiments were replicated at least three times, independently.

Table 1. Oligonucleotide primers used in quantitative real-time PCR.

\begin{tabular}{cccc}
\hline Primer & Primer Length & Sequence $\mathbf{( 5}^{\prime} \mathbf{- 3}^{\prime} \mathbf{)}$ & Reference \\
\hline SAA1/2 F & $23 \mathrm{mer}$ & CTGCCTGCCAAATACTGAGAGTC & {$[5]$} \\
SAA1/2 R & $25 \mathrm{mer}$ & CCACTTCCAAGTTCCTGTTTATTAC & \\
SAA3 F & $23 \mathrm{mer}$ & GCTGGCCTGCCTAAAAGATACTG & {$[5]$} \\
SAA3 R & $24 \mathrm{mer}$ & GCATTTCACAAGTATTTATTCAGC & \\
GAPDH F & $19 \mathrm{mer}$ & TGCACCACCAACTGCTTAG & {$[17]$} \\
GAPDH R & $19 \mathrm{mer}$ & GGATGCAGGGATGATGTTC & \\
\hline
\end{tabular}

SAA, serum amyloid A; GAPDH, glyceraldehyde-3-phosphate dehydrogenase.

\subsection{Production of Anti-SAA1 Rabbit Serum}

An anti-SAA1 serum was produced in a rabbit by immunization with a synthetic SAA1 peptide (AAEKISDGREAFOE), which was generated by Eurofins Genomics (Tokyo, Japan) (Figure 1). An anti-SAA3 rabbit serum generated previously [18] was also used in this study.

\subsection{IFA (Indirect Immunofluorescence Assay)}

To examine SAA1 and SAA3 protein expression levels in cells stimulated with LPS and LTA, IFA was carried out. NMuMG cells were cultured on glass coverslips (\#S2441, Matsunami Glass, Kishiwada, Japan) in 6-well plates (\#140675, Thermo Fisher Scientific) and incubated for $15 \pm 1 \mathrm{~h}$ before experiments. LPS and LTA were dissolved to a concentration of $10 \mu \mathrm{g} / \mathrm{mL}$ in DMEM with $2 \%$ FBS and added to the cells. After incubation for 4,8 , and $12 \mathrm{~h}$ at $37^{\circ} \mathrm{C}$, the cells were washed with PBS, incubated in $800 \mu \mathrm{L}$ of cold $100 \%$ methanol for $5 \mathrm{~min}$, and dried. Then, the cells were blocked with $5 \%$ non-fat dried skim milk in PBS for 30 min at room temperature. Anti-SAA1 or anti-SAA3 rabbit serum [18] was used as the first antibody. The cells were incubated with the antibody diluted in PBS (1:50) containing $2 \%$ FBS in a humidified chamber for $1 \mathrm{~h}$ at room temperature and then washed with PBS. Then, the cells were incubated with the secondary antibody, FITC-goat anti-rabbit IgG $(\mathrm{H}+\mathrm{L})$ (1:50, ZYMED Laboratories, South San Francisco, CA, USA) in a humidified chamber for $1 \mathrm{~h}$ at room temperature. After washing with PBS, the coverslip was mounted with a drop of $50 \%$ glycerol in PBS on a glass slide and sealed with nail polish. The cells were examined with an epifluorescence microscope (ECLIPSE 80i, Nikon, Tokyo, Japan), and the images were captured with ACT-1C software for the DXM 1200C camera (Nikon). The fluorescence of the cells was measured in five or more visual fields randomly selected by using ImageJ (National Institutes of Health, Bethesda, MD, USA). It was normalized to the fluorescence of each respective control and fold-changes relative to control levels were determined.

\subsection{WB (Western Blotting)}

To examine SAA1 and SAA3 protein expression levels in cell supernatants stimulated with LPS and LTA, WB analysis was carried out. NMuMG cells were cultured in the same manner as mentioned above for the analysis of mRNA expression levels. LPS and LTA were dissolved to a concentration of $10 \mu \mathrm{g} / \mathrm{mL}$ in DMEM with $2 \%$ FBS and added to the cells. After incubation for $0,6,12$, and $24 \mathrm{~h}$ at $37^{\circ} \mathrm{C}, 1.0 \mathrm{~mL}$ of cell supernatant was collected and centrifuged at 20,000 $\times \mathrm{g}$ for $60 \mathrm{~min}$ at $4^{\circ} \mathrm{C}$ using an MX-301 centrifuge (Tomy, Tokyo, Japan). Sample precipitates were dissolved in sodium dodecyl sulfate (SDS) sample buffer $(0.125 \mathrm{M}$ Tris-HCl, pH 6.8, 10\% 2-mercaptoethanol, $4 \%$ SDS, $10 \%$ glycerol, and $0.01 \%$ bromophenol blue) and boiled for $5 \mathrm{~min}$ before electrophoresis. These samples were loaded onto a $10 \%$ or $12.5 \%$ SDS-polyacrylamide gel and electrophoresed. The proteins were transferred onto a polyvinylidene difluoride membrane (Immobilon-P, Millipore, Cork, Ireland), blocked with $5 \%$ nonfat milk in Tris-buffered saline (0.01 M Tris- $\mathrm{HCl}(\mathrm{pH} 8.0)$ 
and $0.15 \mathrm{M} \mathrm{NaCl}$ ) containing $0.1 \%$ Tween-20 (TBST), and incubated for $30 \mathrm{~min}$ at room temperature. Subsequently, the membrane was incubated with the primary anti-mouse SAA1 rabbit polyclonal antibody (1:500, \#PAA885Mu01, Cloud-Clone, Houston, TX, USA) or anti-SAA3 rat monoclonal antibody [JOR110A] (1:50, \#ab231680, Abcam, Cambridge, UK) diluted with $1 \%$ nonfat dried skim milk in TBST for $1 \mathrm{~h}$ at room temperature. After washing three times with TBST, the membrane was incubated with anti-rabbit IgG, HRPlinked antibody (1:2000, \#7074, Cell Signaling Technology, Danvers, MA, USA) or anti-rat IgG, HRP-linked species-specific whole antibody from goat (1:2000, NA935, GE Healthcare, Buckinghamshire, UK) diluted with TBST for $1 \mathrm{~h}$ at room temperature. After washing three times, the peroxidase activity was detected using a Pierce ECL Plus Western Blotting Substrate (Thermo Fisher Scientific) and visualized by a LAS4000mini UV imager (Fujifilm, Tokyo, Japan). Recombinant murine SAA1 (rSAA1) and rSAA3 [19] were used as antigens for positive controls.

\subsection{Statistical Analysis}

Data were collected from at least three independent experiments and expressed as the mean \pm standard deviation. Data were analyzed for statistical significance by one-way analysis of variance and the Tukey's post hoc test.

\section{Results}

\subsection{Relative Saa1 and Saa3 mRNA Expression Levels}

Saa3 mRNA expression levels were significantly increased $\sim 6.5$ - and $\sim 3$-fold by LPS and LTA, respectively, after stimulation for $2 \mathrm{~h}$ (Figure 2). In contrast, Saa1 mRNA expression levels were not significantly altered by either LPS or LTA stimulation.

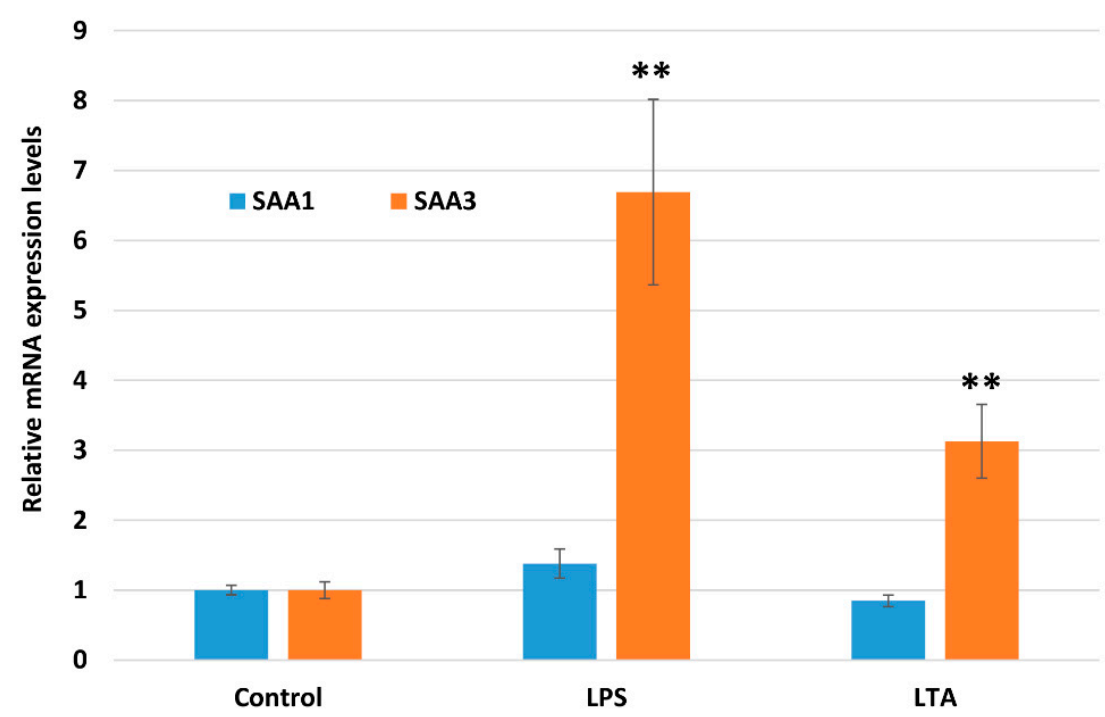

Figure 2. Comparison of Saa1 and Saa3 mRNA expression levels in NMuMG cells treated with lipopolysaccharide (LPS) and lipoteichoic acid (LTA). Data are presented as the mean \pm standard deviation of four independent experiments. Asterisks indicate significant difference compared with control levels: ${ }^{* *} p<0.01$. NMuMG, normal murine mammary gland.

\subsection{SAA1 and SAA3 Protein Expression Levels}

In IFA, after a $4 \mathrm{~h}$ stimulation, there was no significant increase in the fluorescence associated with SAA1 or SAA3 (Figure 3). The SAA1 fluorescence intensity signal did not change significantly at any other time point of the experiment with LPS stimulation ( $8 \mathrm{~h}$ and $12 \mathrm{~h}$; Figure 3A,B). However, the fluorescence intensity of the SAA3 protein increased significantly $~ 1.4$ - and 1.6-fold after LPS stimulation for 8 and $12 \mathrm{~h}$, respectively (Figure 3C,D). Furthermore, after $12 \mathrm{~h}$ stimulation with LTA, the fluorescence intensity of the SAA3 signal 
also significantly increased 1.2-fold (Figure 3D). In the WB experiments, no expression of the SAA1 protein was observed after stimulations with LPS or LTA (Figure 4A). SAA3 protein expression was observed after $6 \mathrm{~h}$ stimulation with LPS, and it increased further after $12 \mathrm{~h}$ and $24 \mathrm{~h}$ stimulations (Figure 4B). In addition, SAA3 expression was observed after $24 \mathrm{~h}$ LTA stimulation.

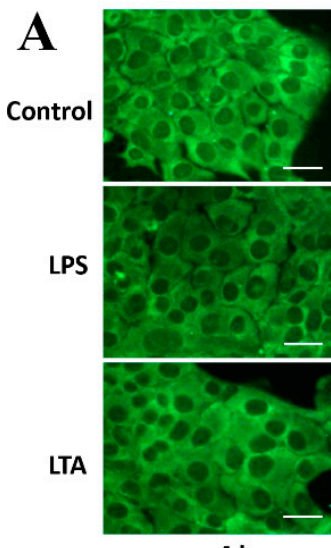

$4 \mathrm{~h}$

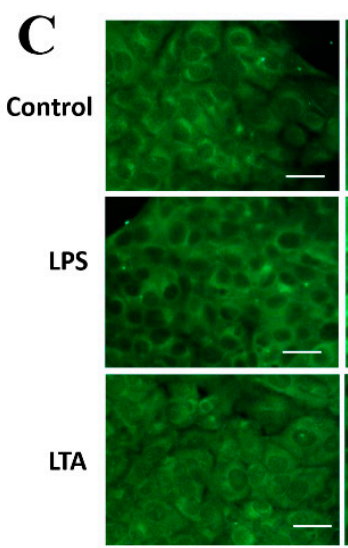

$4 \mathrm{~h}$

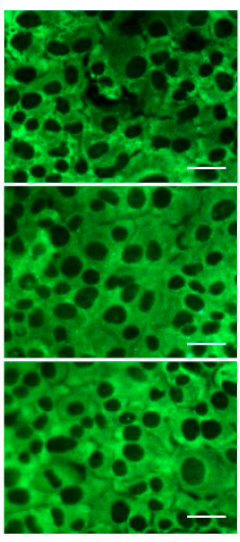

$8 \mathrm{~h}$

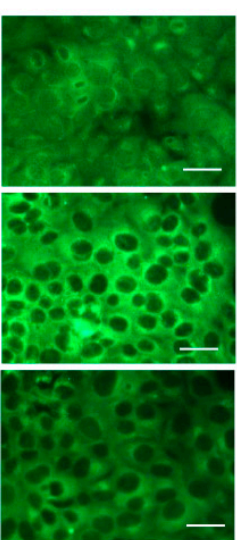

$8 \mathrm{~h}$

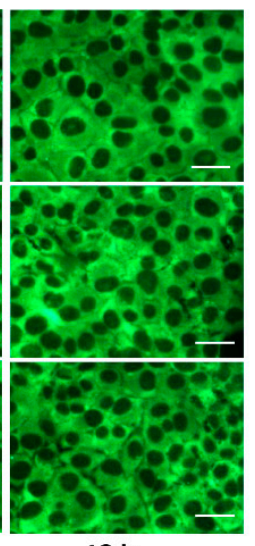

$12 \mathrm{~h}$

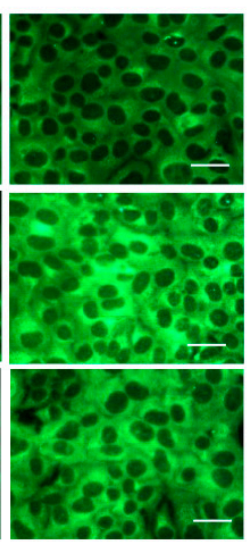

$12 \mathrm{~h}$

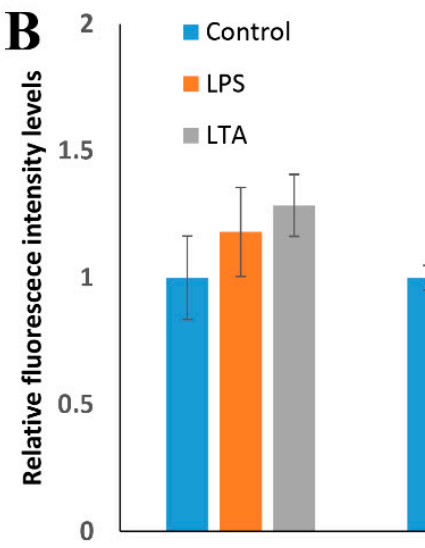

4h

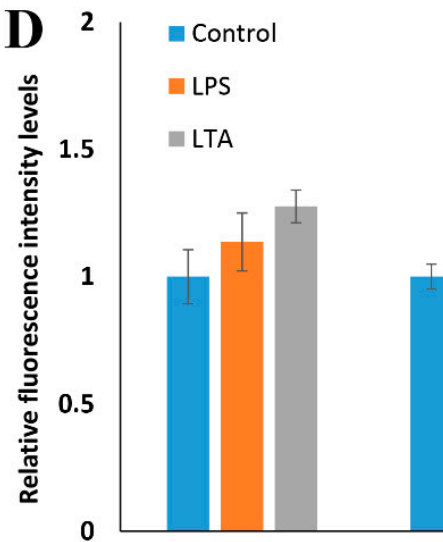

$4 h$

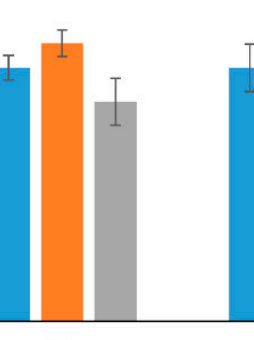

8h

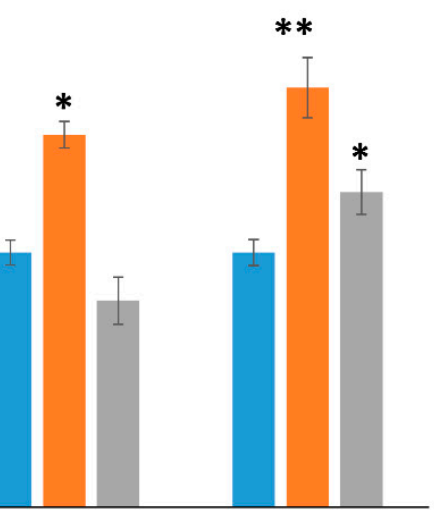

$8 h$

$12 \mathrm{~h}$

Figure 3. Comparison of SAA1 (A,B) and SAA3 (C,D) protein expression levels in NMuMG cells treated with lipopolysaccharide (LPS) or lipoteichoic acid (LTA) by immunofluorescence analysis (IFA). (A,C) Fields of view where fluorescence intensity was measured. Scale bar $=20 \mu \mathrm{m}$. (B,D) The relative SAA1 and SAA3 protein expression levels in NMuMG cells following stimulation with LPS or LTA were normalized to those in untreated, control cells. Data are presented as the mean fluorescence of five or more random locations with vertical bars representing standard deviation. Asterisks indicate significant difference compared with control levels: ${ }^{*} p<0.05,{ }^{* *} p<0.01$. NMuMG, normal murine mammary gland. 
$\mathbf{A}_{\mathrm{kDa}}$

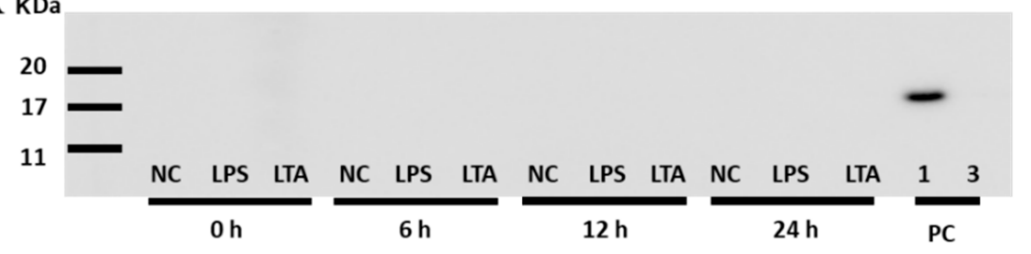

B

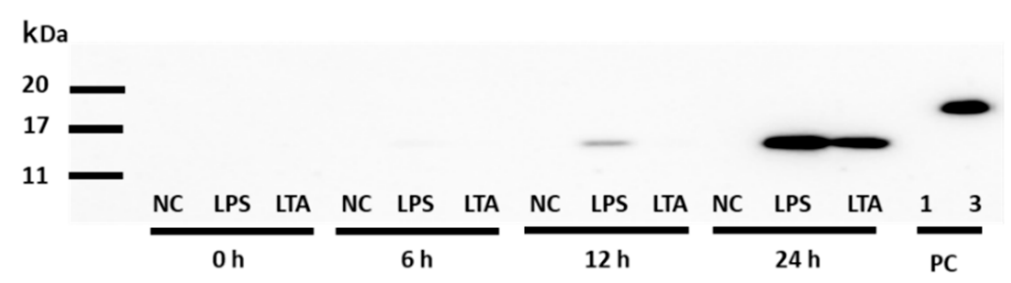

Figure 4. Detection of SAA1 and SAA3 protein expression in NMuMG cell supernatants treated with lipopolysaccharide (LPS) or lipoteichoic acid (LTA) by Western blot. (A) Detection of SAA1 in the cell supernatant. Membranes were incubated with the primary anti-mouse SAA1 antibody (dilution of 1:500, 60 s exposure time). (B) Detection of SAA3 in the cell supernatant. Membranes were incubated with the primary anti-mouse SAA3 antibody (dilution of 1:50, $120 \mathrm{~s}$ exposure time). PC, positive control; 1, recombinant murine SAA1 (rSAA1); 3, rSAA3; NMuMG, normal murine mammary gland.

\section{Discussion}

Eckhardt et al., demonstrated that Saa1/2 mRNA was detected in the colon and ileum epithelium of conventionally raised mice and expression of Saa3 mRNA overlapped in vivo [23]. Saa3 mRNA expression, strongly increased, but not Saa1 mRNA, by LPS in mouse colonic epithelial CMT-93 cells [23]. In this study, we revealed that LPS and LTA induced Saa3 mRNA and protein expression in mouse mammary epithelium. Our findings are in accordance with previous studies that demonstrated up-regulation of Saa3 mRNA expression by bacterial antigens in mouse epithelial cells, such as colonic epithelial CMT93 cells $[16,23,24]$, type-II alveolar epithelial MLE-15 and T7 cells [17], and pulmonary mucosal epithelial Club (Clara) C22 cells [18].

The quantitative real-time PCR analysis showed that Saa3 mRNA expression was significantly enhanced in NMuMG cells treated with LPS. Although LTA also enhanced Saa3 mRNA expression, its effect was weaker than that of LPS stimulation. In contrast, Saa1 mRNA expression was not significantly changed by either treatment. These results suggest the existence of bacterial antigen, similar to LPS, which can induce Saa3 mRNA expression in mouse mammary epithelial cells. However, Saa1 mRNA is unlikely to be induced by such bacterial antigen. This result is consistent with previous studies of the effects of LPS and LTA on Saa3 mRNA expression levels in epithelial cell lines including CMT93, MLE-15, T7, and C22 cells, although Saa1 mRNA was detectable and expressed constantly [16-18,23]. It is highly likely that the properties of the Saa3 gene are similar in various mouse mucosal epithelial cells. Besides, Burvenich et al. reported that the bovine mammary gland was highly sensitive to a low dose of LPS from E. coli [24]. Therefore, it is likely that mouse mammary epithelium is also highly sensitive to LPS stimulation.

In IFA and WB analysis, LPS induced SAA3 protein expression more strongly than LTA. In contrast, SAA1 protein expression did not change upon the stimulation with LPS or LTA compared to the level in control cells, which was in agreement with the results of real-time PCR. These results indicate that NMuMG responded to the stimulation with LPS cells by up-regulating Saa3 rather than Saa1 mRNA and protein expression levels. Considering the results of real-time PCR, it can be concluded that SAA3 protein expression was induced by bacterial antigen stimulation.

In mouse colonic epithelial CMT-93 cells, Saa3 mRNA expression was induced strongly by the inoculation with E. coli, but not with Staphylococcus aureus [16]. Moreover, in mouse pulmonary mucosal epithelial C22 cells, the induction of Saa3 mRNA expression was 
stronger after LPS than after LTA treatment [18]. These observations suggest that the local immune system of mammary epithelial cells is more sensitive to LPS stimulation than to LTA stimulation, and this differential sensitivity resembles that in other epithelial cells. In this study, we used cultured cells that fail its native characteristics of polarity of the mammary epithelium. Further investigations are required for identification of interaction between bacterial infection and SAA3 expression in mouse mammary epithelium in vivo. In addition, previous studies suggested that mouse SAA3 may play a role in lung development [10], obesity and immunometabolic homeostasis [11], bone homeostasis [15], and metastasis [14,25], as well as in local immunity in a wide variety of epithelium [12,13,16-18]. For deep understanding of SAA3 in physiology and pathology in hosts, multifunctional roles of SAA3 should be defined.

In bovine mastitis, the isolated pathogens from the infected area vary, depending on the study areas location and age. For example, Riekerink et al. [26] showed that the main pathogens in the tissue affected by bovine mastitis were $S$. aureus $(10.3 \%), E$. coli $(8.4 \%)$, and S. uberis (6.3\%). Oliveira et al., [27] detected E. coli (22.5\%), streptococci $(12.8 \%)$, and Klebsiella spp. (6.9\%); whereas Verbeke et al. [28] showed the presence of $S$. uberis (18.2\%) and E. coli (15.5\%). Among them, Oliveira et al. [27] have reported a positive correlation between cases with systemic severe signs of illness, such as depression, anorexia, dehydration, or fever, and E. coli infection. In that study, it was suspected that the immune system of the mammary epithelium was more sensitive to LPS from Gram-negative bacteria than to LTA from Gram-positive bacteria. Up-regulation of bovine SAA3 expression from mammary epithelial cells were stimulated with LPS, and LTA [29-31]. It has been reported that the aggravation of mastitis associated with the presence of E. coli is not caused by the bacteria themselves, but by LPS and inflammatory cytokines of the host [32,33]. One of the major mediators involved in the endotoxic shock that aggravates mastitis is tumor necrosis factor- $\alpha$ (TNF- $\alpha)$, and this inflammatory cytokine is down-regulated by interferon$\gamma$ [33]. An in vivo experiment in cows demonstrated that all animals in the prophylactic group, which received IFN- $\gamma$ before the experimental $E$. coli challenge, survived acute $E$. coli mastitis. On the other hand, in the untreated group, many cows developed clinical mastitis and dead from endotoxemia [33]. Ather et al. [10] showed that CD4 ${ }^{+} \mathrm{T}$ cells from the Saa3 knockout mouse exhibited increased levels of IL-17A and decreased levels of IL-5, IL-10, IL-13, and IFN- $\gamma$. It is possible that the presence of SAA3 protects the host from the endotoxic shock caused by acute $E$. coli mastitis, because SAA3 increases the expression of INF- $\gamma$ and suppresses the expression of TNF- $\alpha$ and local production of SAA3 by colonic epithelial cells enhanced neutrophilic IL-22 production and, bactericidal activity, and reduced apoptosis [12]. Furthermore, previous studies suggested that bovine SAA3 is also associated with involution and remodeling of the mammary gland [34-36]. It is likely that SAA3 plays such functional roles not only in the mammary gland epithelium of cattle but also in that of mice.

\section{Conclusions}

This study suggests that SAA3 expression is up-regulated in the mammary epithelium in response to the exposure to bacterial antigens. SAA3 may play a role in the local defense against bacterial infections, especially Gram-negative bacteria more strongly than Gram-positive bacteria, in mouse mammary epithelium.

Author Contributions: Conceptualization, Y.I.; investigation, S.K. and K.S.; data curation, S.K. and K.S.; writing-original draft preparation, S.K. and K.S.; writing-review and editing, A.O. and Y.I.; supervision, Y.I.; project administration, Y.I.; funding acquisition, Y.I. All authors have read and agreed to the published version of the manuscript.

Funding: This research was partly funded by JSPS KAKENHI (16H05027); and by the Grant for Joint Research Program of the Research Center for Zoonosis Control, Hokkaido University, from the Ministry of Education, Culture, Sports, Science, and Technology, Japan.

Institutional Review Board Statement: Not applicable. 
Informed Consent Statement: Not applicable.

Data Availability Statement: Data are available on request the corresponding author.

Conflicts of Interest: The authors declare no conflict of interest. The funders had no role in the design of the study; in the collection, analyses, or interpretation of data; in the writing of the manuscript, or in the decision to publish the results.

\section{References}

1. Caughey, B.; Baron, G.S. Are cheetahs on the run from prion-like amyloidosis? Proc. Natl. Acad. Sci. USA 2008, 105, 7113-7114. [CrossRef] [PubMed]

2. Obici, L.; Merlini, G. AA amyloidosis: Basic knowledge, unmet needs and future treatments. Swiss Med. Wkly. 2012, 142, w13580. [CrossRef]

3. Bellotti, V.; Chiti, F. Amyloidogenesis in its biological environment: Challenging a fundamental issue in protein misfolding diseases. Curr. Opin. Struc. Biol. 2008, 18, 771-779. [CrossRef] [PubMed]

4. Biaoxue, R.; Hua, L.; Wenlong, G.; Shuanying, Y. Increased serum amyloid A as potential diagnostic marker for lung cancer: A meta-analysis based on nine studies. BMC Cancer 2016, 16, 836. [CrossRef]

5. Eckersall, P.D.; Bell, R. Acute phase proteins: Biomarkers of infection and inflammation in veterinary medicine. Vet. J. 2010, 185, 23-27. [CrossRef] [PubMed]

6. Uhlar, C.M.; Whitehead, A.S. Serum amyloid A, the major vertebrate acute-phase reactant. Eur. J. Biochem. 1999, 265, 501-523. [CrossRef] [PubMed]

7. Chiba, T.; Han, C.Y.; Vaisar, T.; Shimokado, K.; Kargi, A.; Chen, M.H.; Wang, S.; McDonald, T.O.; O'Brien, K.D.; Heinecke, J.W.; et al. Serum amyloid A3 does not contribute to circulating SAA levels. J. Lipid Res. 2009, 50, 1353-1362. [CrossRef] [PubMed]

8. Meek, R.L.; Benditt, E.P. Amyloid A gene family expression in different mouse tissues. J. Exp. Med. 1986, 164, 2006-2017. [CrossRef]

9. Reigstad, C.S.; Lundén, G.Ö.; Felin, J.; Bäckhed, F. Regulation of serum amyloid A3 (SAA3) in mouse colonic epithelium and adipose tissue by the intestinal microbiota. PLoS ONE 2009, 4, e5842. [CrossRef]

10. Ather, J.L.; Dienz, O.; Boyson, J.E.; Anathy, V.; Amiel, E.; Poynter, M.E. Serum amyloid A3 is required for normal lung development and survival following influenza infection. Sci. Rep. 2018, 8, 16571. [CrossRef]

11. Ather, J.L.; Poynter, M.E. Serum amyloid A3 is required for normal weight and immunometabolic function in mice. PLoS ONE 2018, 13, e0192352. [CrossRef]

12. Zhang, G.; Liu, J.; Wu, L.; Fan, Y.; Sun, L.; Qian, F.; Chen, D.; Ye, R.D. Elevated expression of serum amyloid A 3 protects colon epithelium against acute injury through TLR2-dependent induction of neutrophil IL-22 expression in a mouse model of colitis. Front. Immunol. 2018, 9, 1503. [CrossRef]

13. Fan, Y.; Zhang, G.; Vong, C.T.; Ye, R.D. Serum amyloid A3 confers protection against acute lung injury in Pseudomonas aeruginosainfected mice. Am. J. Physiol. Lung Cell. Mol. Physiol. 2020, 318, L314-L322. [CrossRef]

14. Hiratsuka, S.; Watanabe, A.; Sakurai, Y.; Akashi-Takamura, S.; Ishibashi, S.; Miyake, K.; Shibuya, M.; Akira, S.; Aburatani, H.; Maru, Y. The S100A8-serum amyloid A3-TLR4 paracrine cascade establishes a pre-metastatic phase. Nat. Cell Biol. 2008, 10, 1349-1355. [CrossRef]

15. Thaler, R.; Sturmlechner, I.; Spitzer, S.; Riester, S.M.; Rumpler, M.; Zwerina, J.; Klaushofer, K.; van Wijnen, A.J.; Varga, F. Acute-phase protein serum amyloid A3 is a novel paracrine coupling factor that controls bone homeostasis. FASEB J. 2015, 29, 1344-1359. [CrossRef]

16. Shigemura, H.; Ishiguro, N.; Inoshima, Y. Up-regulation of MUC2 mucin expression by serum amyloid A3 in mouse colonic epithelial cells. J. Vet. Med. Sci. 2014, 76, 985-991. [CrossRef]

17. Iwata, A.; Shimizu, K.; Kawasaki, H.; Okada, A.; Inoshima, Y. Lipopolysaccharide and lipoteichoic acid enhance serum amyloid A3 mRNA expression in murine alveolar epithelial cells. J. Vet. Med. Sci. 2019, 81, 1409-1412. [CrossRef]

18. Kawasaki, H.; Murakami, T.; Badr, Y.; Kamiya, S.; Shimizu, K.; Okada, A.; Inoshima, Y. In vitro and ex vivo expression of serum amyloid A3 in mouse lung epithelia. Exp. Lung Res. 2020, 46, 352-361. [CrossRef]

19. Tashiro, M.; Iwata, A.; Yamauchi, M.; Shimizu, K.; Okada, A.; Ishiguro, N.; Inoshima, Y. The N-terminal region of serum amyloid A3 protein activates NF- $\mathrm{KB}$ and up-regulates MUC2 mucin mRNA expression in mouse colonic epithelial cells. PLoS ONE 2017, 12, e0181796. [CrossRef]

20. Johansson, M.E.V.; Phillipson, M.; Petersson, J.; Velcich, A.; Holm, L.; Hansson, G.C. The inner of the two Muc2 mucin-dependent mucus layers in colon is devoid of bacteria. Proc. Natl. Acad. Sci. USA 2008, 105, 15064-15069. [CrossRef]

21. Avery-Cooper, G.; Doerr, M.; Gilbert, R.W.D.; Youssef, M.; Richard, A.; Huether, P.; Viloria-Petit, A. Par6 is an essential mediator of apoptotic response to transforming growth factor beta in NMuMG immortalized mammary cells. Cancer Cell Int. 2014, 14, 19. [CrossRef] [PubMed]

22. Yuan, J.S.; Reed, A.; Chen, F.; Stewart, C.N., Jr. Statistical analysis of real-time PCR data. BMC Bioinform. 2006, 7, 85. [CrossRef] [PubMed] 
23. Eckhardt, E.R.M.; Witta, J.; Zhong, J.; Arsenescu, R.; Arsenescu, V.; Wang, Y.; Ghoshal, S.; de Beer, M.C.; de Beer, F.C.; de Villiers, W.J.S. Intestinal epithelial serum amyloid A modulates bacterial growth in vitro and pro-inflammatory responses in mouse experimental colitis. BMC Gastroenterol. 2010, 10, 133. [CrossRef] [PubMed]

24. Burvenich, C.; Bannerman, D.D.; Lippolis, J.D.; Peelman, L.; Nonnecke, B.J.; Kehrli, M.E., Jr.; Paape, M.J. Cumulative physiological events influence the inflammatory response of the bovine udder to Escherichia coli infections during the transition period. J. Dairy Sci. 2007, 90, E39-E54. [CrossRef]

25. Hansen, M.T.; Forst, B.; Cremers, N.; Quagliata, L.; Ambartsumian, N.; Grum-Schwensen, B.; Klingelhöfer, J.; Abdul-Al, A.; Herrmann, P.; Osterland, M.; et al. A link between inflammation and metastasis: Serum amyloid A1 and A3 induce metastasis, and are targets of metastasis-inducing S100A4. Oncogene 2015, 34, 424-435. [CrossRef] [PubMed]

26. Riekerink, R.G.M.O.; Barkema, H.W.; Kelton, D.F.; Scholl, D.T. Incidence rate of clinical mastitis on Canadian dairy farms. J. Dairy Sci. 2008, 91, 1366-1377. [CrossRef]

27. Oliveira, L.; Hulland, C.; Ruegg, P.L. Characterization of clinical mastitis occurring in cows on 50 large dairy herds in Wisconsin. J. Dairy Sci. 2013, 96, 7538-7549. [CrossRef]

28. Verbeke, J.; Piepers, S.; Supre, K.; Vliegher, S.D. Pathogen-specific incidence rate of clinical mastitis in Flemish dairy herds, severity, and association with herd hygiene. J. Dairy Sci. 2014, 97, 6926-6934. [CrossRef]

29. Larson, M.A.; Weber, A.; Weber, A.T.; McDonald, T.L. Differential expression and secretion of bovine serum amyloid A3 (SAA3) by mammary epithelial cells stimulated with prolactin or lipopolysaccharide. Vet. Immunol. Immunopathol. 2005, 107, 255-264. [CrossRef]

30. Larson, M.A.; Weber, A.; McDonald, T.L. Bovine serum amyloid A3 gene structure and promoter analysis: Induced transcriptional expression by bacterial components and the hormone prolactin. Gene 2006, 380, 104-110. [CrossRef]

31. Weber, A.; Weber, A.T.; McDonald, T.L.; Larson, M.A. Staphylococcus aureus lipotechoic acid induces differential expression of bovine serum amyloid A3 (SAA3) by mammary epithelial cells: Implications for early diagnosis of mastitis. Vet. Immunol. Immunopathol. 2006, 109, 79-83. [CrossRef]

32. Burvenich, C.; van Merris, V.; Mehrzad, J.; Diez-Fraile, A.; Duchateau, L. Severity of E. coli mastitis is mainly determined by cow factors. Vet. Res. 2003, 34, 521-564. [CrossRef]

33. Sordillo, L.M.; Peel, J.E. Effect of interferon- $\gamma$ on the production of tumor necrosis factor during acute Escherichia coli mastitis. J. Dairy Sci. 1992, 75, 2119-2125. [CrossRef]

34. McDonald, T.L.; Larson, M.A.; Mack, D.R.; Weber, A. Elevated extrahepatic expression and secretion of mammary-associated serum amyloid A 3 (M-SAA3) into colostrum. Vet. Immunol. Immunopathol. 2001, 83, 203-211. [CrossRef]

35. Molenaar, A.J.; Harris, D.P.; Rajan, G.H.; Pearson, M.L.; Callaghan, M.R.; Sommer, L.; Farr, V.C.; Oden, K.E.; Miles, M.C.; Petrova, R.S.; et al. The acute-phase protein serum amyloid A3 is expressed in the bovine mammary gland and plays a role in host defence. Biomarkers 2009, 14, 26-37. [CrossRef]

36. Domènech, A.; Parés, S.; Bach, A.; Arís, A. Mammary serum amyloid A3 activates involution of the mammary gland in dairy cows. J. Dairy Sci. 2014, 97, 7595-7605. [CrossRef] 